\title{
AVALIAÇÃO DAS MANIFESTAÇÕES PATOLÓGICAS E REALIZAÇÕES DE ENSAIOS NÃO DESTRUTIVOS E SEMI-DESTRUTIVOS EM PONTES DA CIDADE DO RECIFE/PE
}

\author{
LEITE, ALLAN \\ Mestrando em Engenharia Civil \\ Universidade de Pernambuco \\ PE; Brasil \\ allanleite@gmail.com
}

\author{
NASCIMENTO, FERNANDO \\ Graduado em Engenharia Civil \\ Universidade Católica de Pernambuco \\ PE; Brasil \\ carlosfernando.gn@gmail.com
}

\author{
VALE, LEONARDO \\ Mestrando em Engenharia Civil \\ Universidade Católica de Pernambuco \\ PE; Brasil \\ leodovalle@outlook.com
}

\author{
MACIEL, PEDRO \\ Graduando em Engenharia Civil \\ Universidade Católica de Pernambuco \\ PE; Brasil \\ pedromaciel@gmail.com
}

\author{
ROMA, RODRIGO \\ Mestrando em Engenharia Civil \\ Universidade de Pernambuco \\ PE; Brasil \\ rodrigoroma@gmail.com
}

\author{
ALVES, MATHEUS \\ Graduado em Engenharia Civil \\ Universidade de Pernambuco \\ PE; Brasil \\ matheus_italo@outlook.com
}

\section{RESUMO}

O grande número de pontes modelam a arquitetura e a engenharia de Recife, porém a ausência de vistorias e manutenções provocaram a formação de diversos problemas patológicos e funcionais das mesmas. Foram elaboradas inspeções nas pontes 12 de setembro, José de Barros Lima e Princesa Isabel com o intuito de realizar uma análise qualitativa e quantitativa do estado estrutural e durabilidade destas obras. Além da inspeção visual, foram realizados alguns ensaios não destrutivos e semi-destrutivos como profundidade de carbonatação, indicador de cloretos livres e esclerometria. Assim, na ponte 12 de setembro o Índice Esclerométrico (IE), que resulta na resistência superficial do concreto, variou entre 64,9 a 66,6 MPa. Na ponte Princesa Isabel o (IE) variou entre 35,5 MPa a 51,5 MPa e na ponte José de Barros os resultados do (IE) foram os mesmos da ponte Princesa Isabel. Os resultados de resistência à compressão que variaram entre 17,5 MPa a 37,50 MPa para todas as (OAE'S) - Obras de Artes Especiais/ pontes. A Ponte José de Barros Lima considerada, na análise qualitativa, como crítica de acordo com a NBR 9452, atingiu em sua classificação nota 1. Em suma, todas as pontes apresentaram diversos problemas funcionais e necessitam de um projeto de recuperação para manter suas funcionalidades físicas e mecânicas nos aspéctos de durabilidade e vida útil.

Palavras-chave: pontes; Manifestações patológicas; concreto armado; ensaios não destrutivos e semi destrutivos.

\section{ABSTRACT}

The large number of bridges model Recife's architecture and engineering, but the absence of inspections and maintenance has caused the formation of several pathological and functional problems. Inspections were made in the 12 de Setembro, José de Barros Lima and Princesa Isabel bridges in order to perform a qualitative and quantitative analysis of the structural state and durability of these works. Besides the visual inspection, some non-destructive and semidestructive tests were performed, such as carbonation depth, free chloride indicator and sclerometry. Thus, in the 12 de Setembro bridge the Sclerometric Index (SI), which results in the surface resistance of the concrete, ranged from 64.9 to 66.6 MPa. In the Princesa Isabel bridge the (SI) ranged from 35.5 MPa to 51.5 MPa and in the José de Barros bridge the (SI) results were the same as for Princesa Isabel bridge. The compression strength results ranged from $17.5 \mathrm{MPa}$ to 37.50 MPa for all (SWA'S) - Special Works of Art/bridge. The José de Barros Lima Bridge considered, in the qualitative analysis, as critical according to NBR 9452, reached in its classification score 1 . In short, all the bridges presented several functional problems and needed a recovery project to maintain their physical and mechanical features in terms of durability and useful life.

Keywords: bridges; pathological manifestations; reinforced concrete; non-destructive and semi-destructive tests. 


\section{INTRODUÇÃO}

A cidade do Recife apresenta, em sua geografia, um conjunto de pontes históricas que interligam seus bairros centrais. Recife, possui maior densidade de habitantes do estado de Pernambuco de acordo com o Instituto Brasileiro de Geografia e estatística (IBGE). Nela estão concentrados 46,3\% do estado totalizando 1.637 .834 habitantes em uma área de aproximadamente $220 \mathrm{~km}^{2}$.

O sistema viário do município permite a ligação entre essas ilhas por meio de pontes localizadas por toda região metropolitana cruzando os rios Capibaribe e Beberibe. Considerada de acordo com a NBR 6118 (ABNT, 2014) como uma região de classe de agressividade muito forte, as pontes de Recife são facilmente degradadas principalmente pela concentração de $\mathrm{CO} 2$ (gás carbônico) na atmosfera e íons cloretos gerados pelas movimentações das marés nas preiamar e baixa-mar.

Com o passar do tempo, essas estruturas consideradas (OAE'S) - Obras de Artes Especiais foram apresentando alguns problemas funcionais, sobretudo, acarretando em manifestações patológicas que afetam sua estabilidade. De acordo com Nascimento et al., (2018) a degradação das pontes preocupam os órgãos governamentais, pois os custos envolvidos para a recuperação dessas estruturas são cada vez maiores levando em consideração a complexidade do projeto de recuperação desenvolvido.

Estudos desenvolvidos por Diógenes et al., (2014) evidenciam que medidas devem ser tomadas para que a durabilidade das estruturas de Obras de Artes Especiais seja observada como primordial em relação a forma de construção, de modo que evitem-se gastos desnecessários nos reparos e restaurações futuras além de que, é essencial ter conhecimento sobre estruturas e materiais, em particular através do estudo e análise dos erros acontecidos, que têm resultado em deterioração precoce ou em acidentes.

Alguns fatores agravantes também contribuíram para a situação atual, como é o caso das normas brasileiras mais antigas que vigoravam à época em que as obras foram projetadas e construídas, que não previam os carregamentos nem a intensidade de tráfego atualmente existentes nas rodovias e nos centros urbanos do País; também não consideravam a agressividade ambiental dos locais onde as pontes foram construídas (VITÓRIO; BARROS, 2013; MILANI; KRIPKA; PRAVIA, 2011).

Neste trabalho, procurou-se identificar as principais manifestações patológicas que se apresentam ao longo da vida útil nas estruturas das pontes estudadas, identificando a frequência, a intensidade e as origens desses problemas observados. Além disso, foram realizados alguns ensaios para compreender o comportamento das características estruturais e de durabilidade destas pontes, de modo a fazer uma análise criteriosa sobre o estado dessas estruturas e elaborar planos de manutenção e até mesmo intervenção, caso necessário.

\section{CONCEPÇÃO DAS PONTES}

Nos projetos de engenharia, uma ponte é caracterizada como Obra de Arte Especial (OAE) e recebe essa nomenclatura, pois requer um projeto específico dentro do próprio projeto de uma via.

De acordo com Vitório (2002), ponte é especificada como toda obra de transposição, quando o obstáculo é constituído por água, cabendo-lhe estabelecer a ligação entre duas margens. Quando o obstáculo transposto não é constituído por água, denomina-se a obra de viaduto.

A ponte em suas finalidades tem como principais objetivos: Resistir às solicitações variáveis do tráfego; resistir às solicitações permanentes tais como peso próprio da estrutura, rede de iluminação, pista de rolamento etc; ter em sua composição materiais que vençam os esforços solicitados e que tenham resistência superior a esses esforços. 


\subsection{Componentes estruturais de uma ponte}

Essas esruturas são compostas, geralmente, por três tipos de componentes estruturais: Superestrutura, Mesoestrutura e infraestrutura. De acordo com Vitório (2002) há na (Figura 1) a seguinte representação e definição para cada um desses componentes:

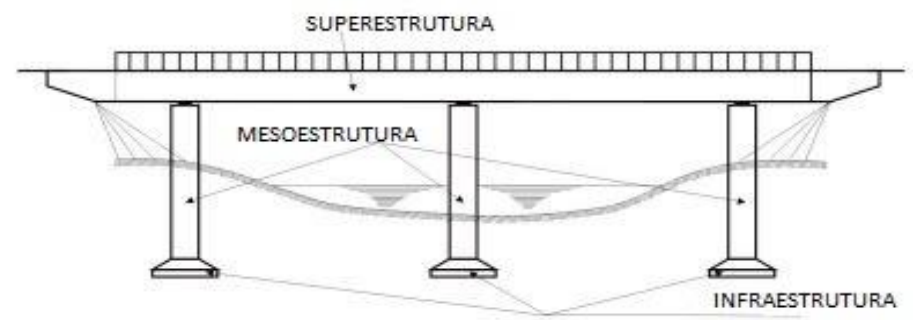

Figura 1: Componentes de uma Obra de Arte Especial

\subsubsection{Superestrutura}

É a camada superior que recebe diretamente os esforços do tráfego transmitindo-as à mesoestrutura. É normalmente denominada de tabuleiro ou estrado.

\subsubsection{Mesoestrutura}

A mesoestrutura, cuja função é conduzir as cargas da superestrutura para as fundações, é constituída pelos pilares, travessas e encontros.

\subsubsection{Infraestrutura}

Compõe os elementos de fundação e tem a finalidade de receber as cargas da estrutura, transmitindo-as para o solo.

\subsubsection{Elementos constituintes de uma ponte}

Com o intuito de proporcionar um melhor entendimento das especificações de serviço de inspeção e restauração em pontes e viadutos, o DNIT 122 (2009) normatiza os elementos que compõe uma OAE, a seguir estão listados alguns deles:

- Aparelhos de apoio;

- Juntas estruturais;

- Dispositivos de segurança;

- Dispositivos de drenagem;

\subsection{Concepção das pontes estudadas}

As pontes do Recife se destacam pela importância de mobilidade e a arquitetura diferente que atrai turistas do mundo todo. Conhecida como a Veneza brasileira, a cidade do Recife é cortada por rios e braços de mar que tornam as pontes elementos fundamentais para o desenvolvimento da capital.

Para a realização deste artigo foram realizadas inspeções visuais na Ponte 12 de Setembro (A), Ponte Princesa Isabel (B) e Ponte José de Barros Lima (C), apresentadas na (Figura 2), com o objetivo de identificar as manifestações patológicas causadas pela corrosão por carbonatação e ataques dos íons cloreto e avaliação da dureza superficial do concreto através do ensaio de esclerometria. 


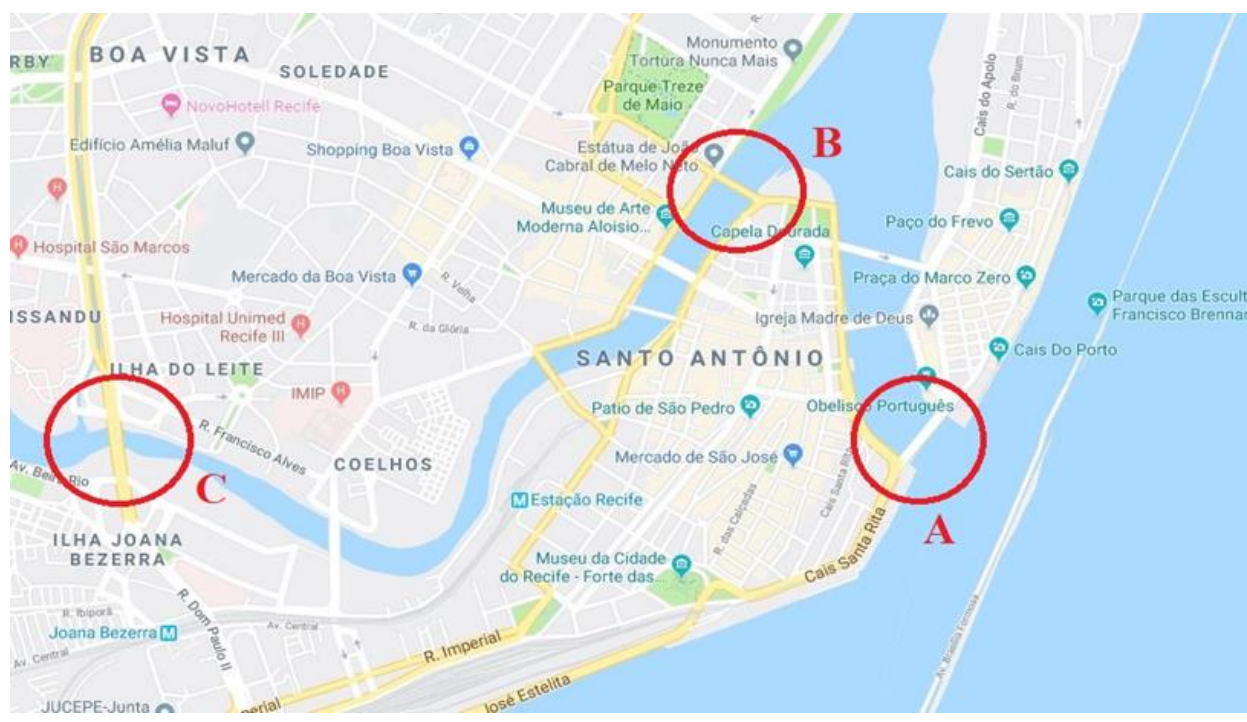

Figura 2: Ponte 12 de Setembro (A), Princesa Isabel (B), José de Barros Lima (C)

As três pontes encontram-se em regiões classificadas como zona de agressividade IV segundo a NBR 6118 (ABNT, 2014), por estarem localizadas em regiões de ações físicas e químicas. Em todas as pontes investigadas foram encontradas manifestações patológicas na estrutura que demonstram necessidade de intervenção.

A falta de manutenção preventiva nas estruturas de concreto armado aumenta o custo, na grande maioria dos casos o problema não é tratado na causa e sim no sintoma. O grande erro é esperar o aparecimento dos primeiros sintomas de manifestação patológica para que seja realizada intervenção.

Em todas as pontes estudadas foram encontrados problemas de infiltração que muitas vezes ocorre por deficiência nas juntas de dilatação ou nos dispositivos de drenagem, a manutenção rotineira nesses dispositivos reduziriam o custo se comparado ao valor gasto na execução do reparo.

\subsubsection{Ponte Princesa Isabel}

Conhecida por interligar a Rua Princesa Isabel e a Rua do Sol, próximo ao Teatro de Santa Isabel, a ponte possui seu nome oficial controverso pois em alguns projetos da Prefeitura do Recife a ponte é identificada como Ponte Santa Isabel. Também é conhecida popularmente como Ponte Princesa Isabel e alguns pesquisadores afirmam que seu nome oficial seja Ponte Pedro II mostrado na (Figura 3).

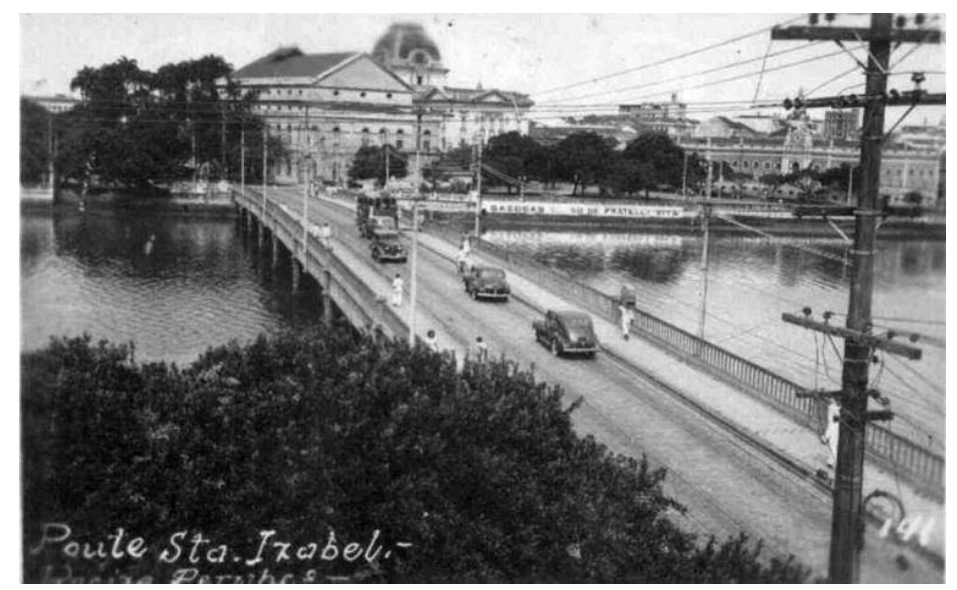

Figura 3: Ponte Princesa Isabel com a estrutura de concreto 
A estrutura da ponte Princesa Isabel é de concreto armado composta por quatro travessas apoiadas em estacas do tipo tubulão. A meso e infraestrutura da ponte é formada por viga travessa e estacas do tipo tubulão. É possível ver a estrutura segundo a NBR 9452 (ABNT, 2016) na (Figura 04) e a estrutura real da ponte na (Figura 5).

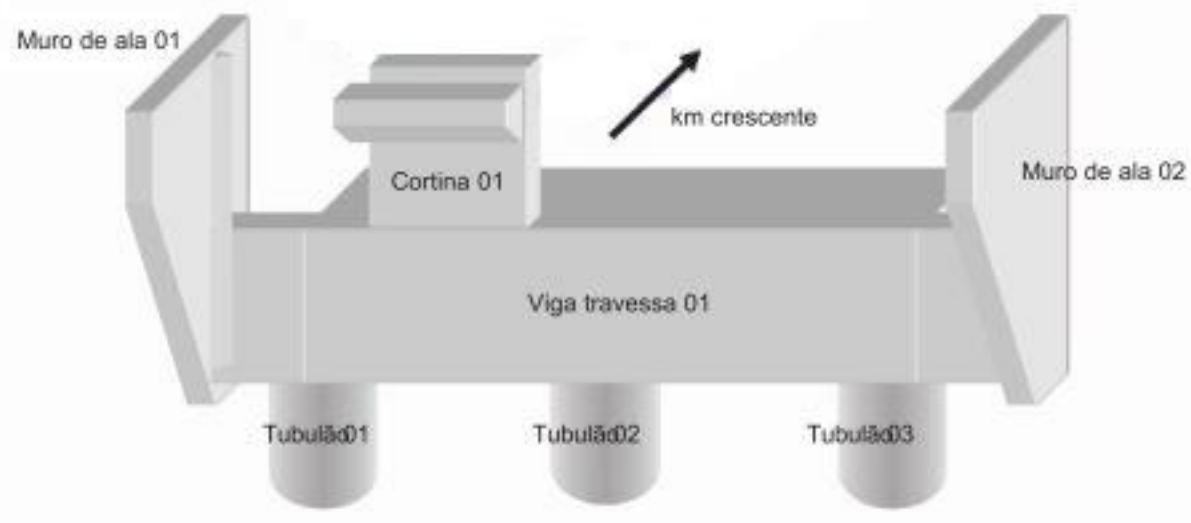

Figura 4: Representação de Meso e Infraestrutura da Ponte Princesa Isabel

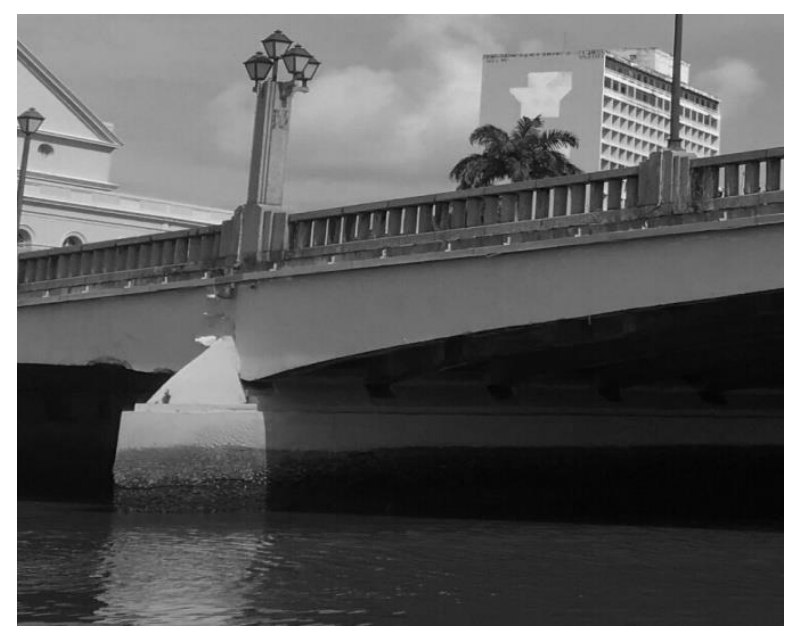

Figura 5: Meso e Infraestrutura da Ponte Princesa Isabel.

\subsubsection{Ponte 12 de Setembro}

Situada interligando os bairros do Recife e São José, foi inaugurada em 1923 com o objetivo de permitir a passagem de embarcações veleiras e transporte ferroviário. Era constituída por três lances: dois fixos (um em cada cabeceira) e um giratório no centro permitindo a passagem de embarcações graças ao seu mecanismo giratório mostrado na (Figura 6).

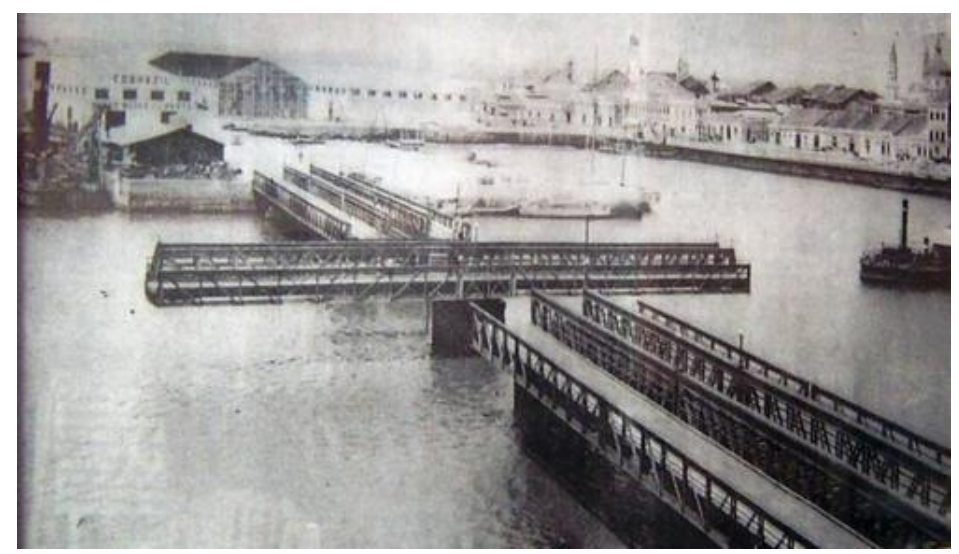

Figura 6: Foto da Ponte Giratória na década de 1930 
O eixo central era utilizado para o tráfego ferroviário enquanto os eixos laterais eram destinados a fluxo de veículos de passeio e pedestres. Em 1971 o mecanismo giratório foi desativado por desuso e a ponte foi desmontada, em seu lugar foi construída uma nova ponte em concreto denominada Ponte 12 de Setembro.

Apesar de ser inaugurada como Ponte 12 de Setembro, a população recifense refere-se a ela como Ponte Giratória e hoje existe a Lei $\mathrm{N}^{\circ}$ 16.916, de 19 de novembro de 2003 que decreta a denominação da ponte como Antiga Ponte Giratória.

Atualmente a Ponte 12 de Setembro apresenta diversas manifestações patológicas oferecendo perigo aos pedestres, veículos de passeio e transporte público coletivo que transitam diariamente sobre a sua estrutura mostrado na (Figura 7).

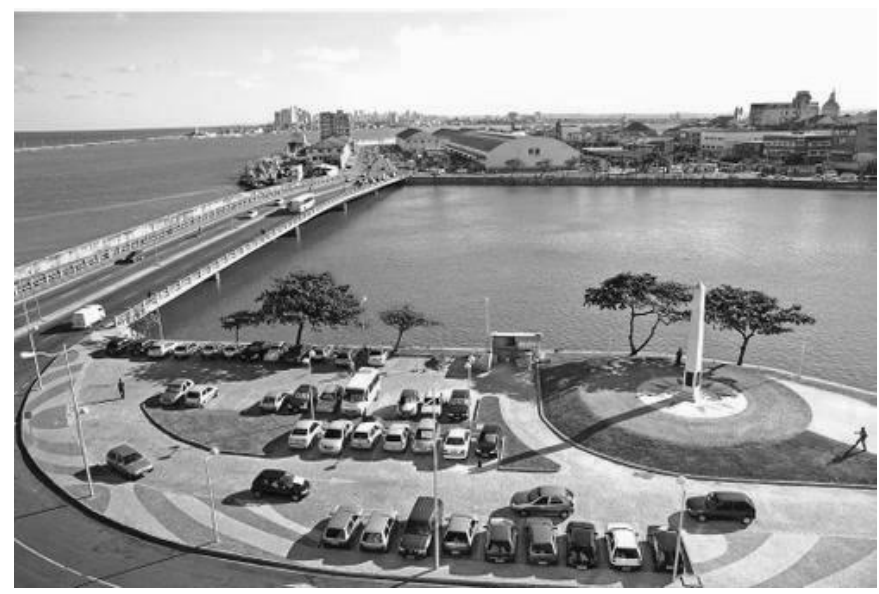

Figura 7: Foto da Ponte 12 de Setembro atualmente

A ponte 12 de Setembro é formada por uma superestrutura de dois tabuleiros em caixão perdido sendo um rodoviário e o outro ferroviário, ambos de caixão perdido apoiados na mesma mesoestrutura do tipo pilar-parede mostrado na (Figura 8).

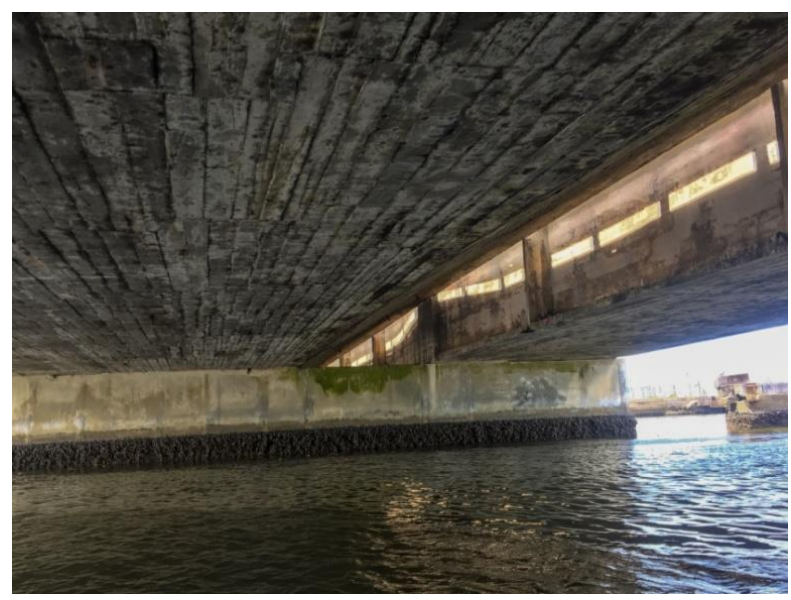

Figura 8: Estrutura da Ponte 12 de Setembro

\subsubsection{Ponte José de Barros Lima}

A ponte José de Barros Lima (Figura 9) interliga os bairros da Joana Bezerra e Ilha do Leite. Sobre ela passa o tráfego da Av. Agamenon Magalhães, uma das principais do Recife, sendo a principal rota para quem deseja chegar à zona sul da cidade e vice versa. 

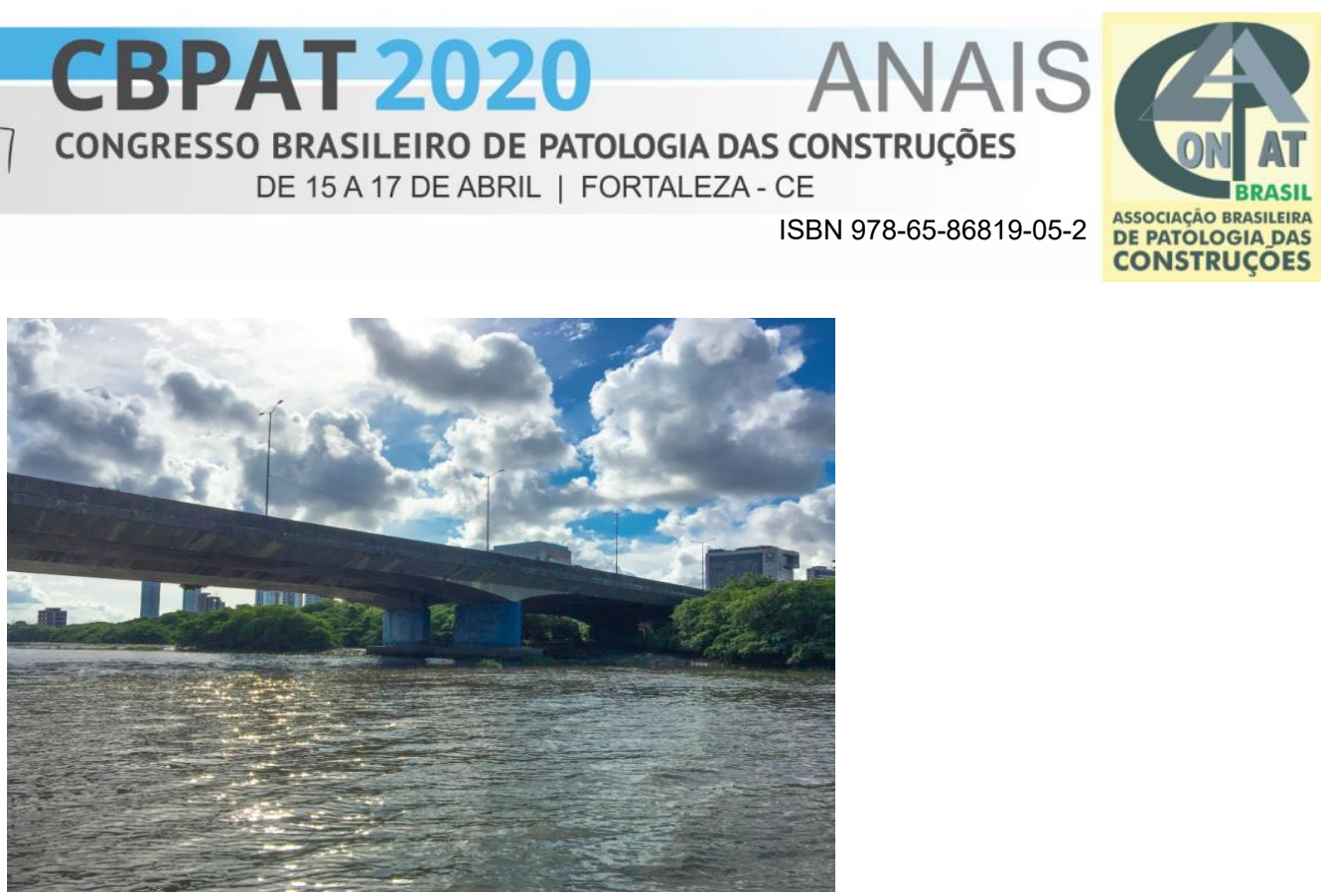

Figura 9: Ponte José de Barros Lima

A superestrutura da ponte José de Barros Lima é formada por dois tabuleiros em caixão perdido apoiados em pilares parede independentes, que está representada na (Figura 10) e pode ser confirmada na (Figura 11). Não foi possível identificar o tipo de fundação devido à preia-mar assim como não foram encontrados registros com tais informações.

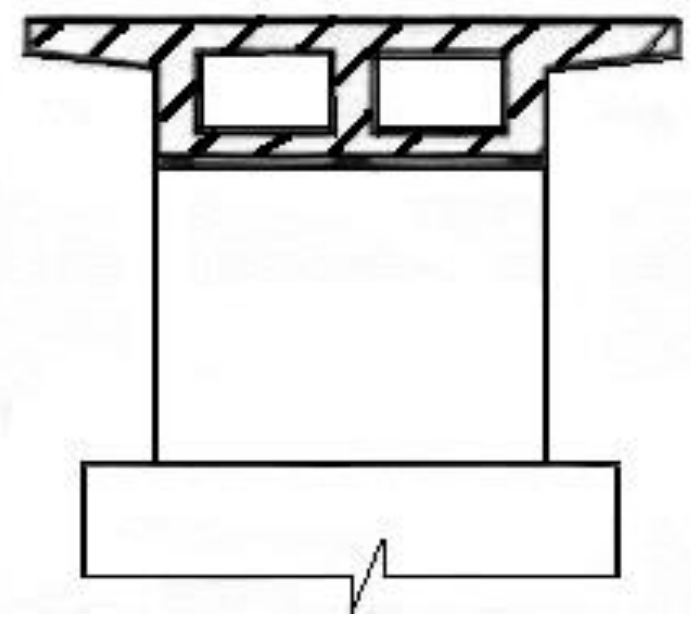

Figura 10: Representação estrutural da Ponte José de Barros Lima

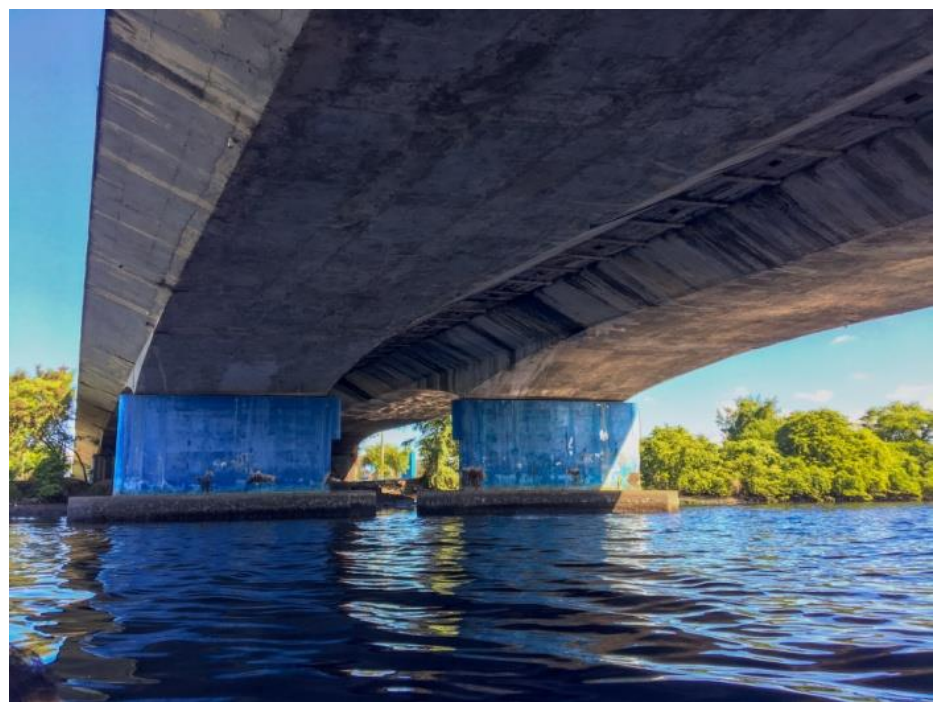

Figura 11: Representação estrutural da Ponte José de Barros Lima 


\section{METODOLOGIA PARA AVALIAÇÃO DAS PONTES}

\subsection{Ensaio de Esclerometria}

O ensaio de esclerometria foi realizado conforme as recomendações técnicas instituídas pela NBR 7584 (ABNT, 2012). Segundo a norma, esse ensaio é um método não destrutivo que mede a dureza superficial do concreto, fornecendo elementos para a avaliação da qualidade do concreto endurecido.

Para a realização do ensaio, foi-se feito uma malha $(4 \times 4)$ apenas para efeito de resultados e ordenação dos impáctos. Não é permitido mais de um impacto sobre um mesmo ponto, caso isto ocorra, o segundo valor lido não pode ser considerado no cálculo dos resultados. Os impactos devem estar uniformemente distribuídos na área de ensaio com uma distância mínima de $3 \mathrm{~cm}$ entre os centros de cada ponto.

O equipamento utilizado para o desenvolvimento das leituras foi o esclerômetro mostrado na (Figura 12). Por se tratar de um aparelho eletrônico, não foi necessário realizar o cálculo para identificação do valor do Índice Esclerométrico que refere-se a resistência superficial do concreto utilizado. Apenas foi executado 16 impactos e o aparelho fornecia os resultados imediatamente.

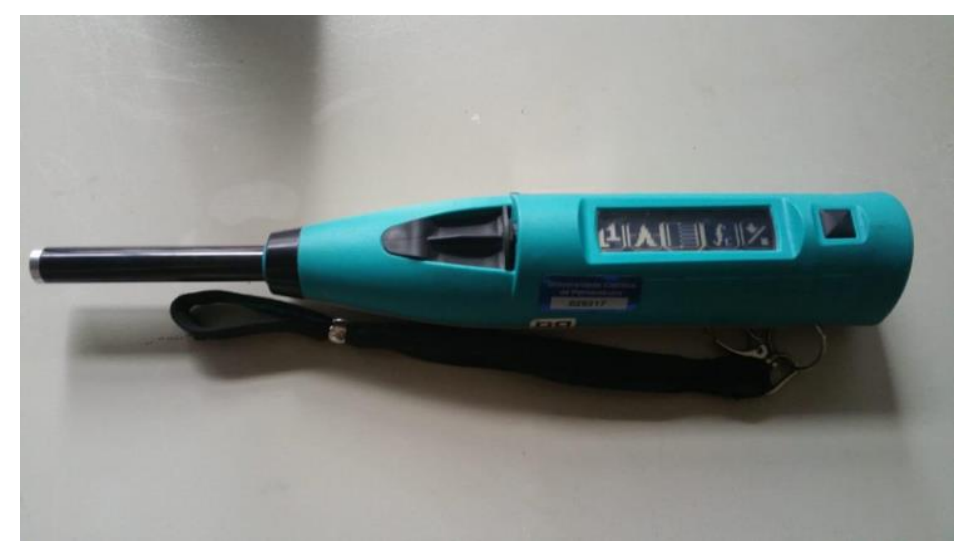

Figura 12: Aparelho eletrônico (esclerômetro)

\subsection{Ensaio por aspersão de fenolftaleína}

Inicialmente prepara-se a solução de $1 \%$ de fenolftaleína misturada em $70 \%$ de álcool etílico para determinação da profundidade de carbonatação. Para a determinação da profundidade de carbonatação foi realizado o ensaio que consiste na quebra de uma área do concreto e posterior aplicação de um indicador químico capaz de alterar a coloração do concreto quando o mesmo está carbonatado. Esse indicador deve ser bem homogeneizado e borrifado na região que foi semidestruída.

A fenolftaleína torna a área do concreto não carbonatada na cor rosada e a área carbonatada permanece incolor sendo este procedimento considerado um ensaio quantitativo. A RILEM CPC-18 (1988) ainda recomenda que a medição da profundidade de carbonatação seja feita 24 horas após a aspersão do indicador químico. A precisão deve ser de 0,5 mm, não sendo levado em conta valores de carbonatação inferiores.

\subsection{Ensaio por aspersão de timolftaleína}

A princípio prepara-se a solução indicadora pesando $1,0 \mathrm{~g}$ de azul de timol, adicionando $21,5 \mathrm{~mL}$ de solução de hidróxido de sódio triturando para solubilizar e, posteriormente, completando o volume com $100 \mathrm{~mL}$ de água. Para a utilização da solução é necessário quebrar a região concretada e com a utilização de luvas e um borrifador, expelir o indicador sobre a área contaminada. Se a área de aplicação da solução estiver com coloração azul, significa que não há cloretos livres e/ou superficiais. 
A identificação dos cloretos dar-se-á pela floculação e precipitação dos mesmos na superfície analisada sendo estes estando em colocação transparente ou amarronzada. O ensaio de aspersão de timolftaleína e nitrato de prata são qualitativos, pois os cloretos são, muitas vezes, evidentes em toda a área do concreto contaminado. A titulação da solução de timolftaleína foi realizada no laboratório de química na Universidade Católica de Pernambuco.

\subsection{Utilização da NBR 9452 - Método de qualidade e parâmetro estrutural}

Com o objetivo de preservar o estado de durabilidade das pontes, viadutos e passarelas de concreto, a NBR 9452 (ABNT, 2016) sistematiza as inspeções e quantifica o grau de melhoramento possibilitando identificar a ponte que está em pior estado de conservação e consequentemente priorizar em uma gestão de manutenção.

A NBR 9452 (ABNT, 2016) classifica uma OAE em três parâmetros quanto à importância em relação à segurança estrutural e gravidade de problemas detectados:

- Parâmetros estruturais;

- Parâmetros funcionais;

- Parâmetros de durabilidade;

Cada um desses parâmetros possui um nível de importância quanto à prioridade de manutenção. Parâmetros estruturais são todos que se referem à capacidade de carga, estado limite e estabilidade da estrutura. Parâmetros funcionais se referem ao mau posicionamento geométrico, má visibilidade ou problema com o gabarito. Por último, o parâmetro de durabilidade refere-se a tudo que comprometa a vida útil da estrutura diminuindo a sua resistência.

Para determinação da classificação das pontes quanto ao seu estado estrutural, condição funcional e durabilidade a NBR 9452 (ABNT, 2016) estabelece alguns parâmetros para facilitar a identificação e classificação dos problemas encontrados. Sendo assim, o (Quadro 1) mostra que a OAE recebe uma nota que varia de 1 a 5 , sendo 1 para crítica e 5 para excelente.

Quadro1 - Classificação da condição de OAE segundo os parâmetros estrutural, funcional e de durabilidade da NBR 9452 (ABNT, 2016)

\begin{tabular}{|c|c|c|c|c|}
\hline $\begin{array}{c}\text { Nota de } \\
\text { classificação }\end{array}$ & Condição & $\begin{array}{l}\text { Caracterização } \\
\text { estrutural }\end{array}$ & $\begin{array}{l}\text { Caracterização } \\
\text { funcional }\end{array}$ & $\begin{array}{c}\text { Caracterização de } \\
\text { durabilidade }\end{array}$ \\
\hline 5 & Excelente & $\begin{array}{l}\text { A estrutura apresenta- } \\
\text { se em condições } \\
\text { satisfatórias, } \\
\text { apresentando defeitos } \\
\text { irrelevantes e isolados. }\end{array}$ & $\begin{array}{l}\text { A OAE apresenta } \\
\text { segurança e conforto } \\
\text { aos usuários. }\end{array}$ & $\begin{array}{l}\text { A OAE apresenta-se em } \\
\text { perfeitas condições, devendo } \\
\text { ser prevista manutenção de } \\
\text { rotina. }\end{array}$ \\
\hline 4 & Boa & $\begin{array}{c}\text { A estrutura apresenta } \\
\text { danos pequenos e em } \\
\text { áreas, sem } \\
\text { comprometer a } \\
\text { segurança estrutural. }\end{array}$ & $\begin{array}{c}\text { A OAE apresenta } \\
\text { pequenos danos que } \\
\text { não chegam a causar } \\
\text { desconforto ou } \\
\text { insegurança ao } \\
\text { usuário. }\end{array}$ & $\begin{array}{l}\text { A OAE apresenta pequenas e } \\
\text { poucas anomalias, que } \\
\text { comprometem sua vida útil, } \\
\text { em região de baixa } \\
\text { agressividade ambiental. }\end{array}$ \\
\hline 3 & Regular & $\begin{array}{l}\text { Há danos que podem } \\
\text { vir a gerar alguma } \\
\text { deficiência estrutural, } \\
\text { mas não há sinais de } \\
\text { comprometimento da } \\
\text { estabilidade da obra. } \\
\text { Recomenda-se } \\
\text { acompanhamento dos } \\
\text { problemas. } \\
\text { Intervenções podem ser } \\
\text { necessárias a médio } \\
\text { prazo. }\end{array}$ & $\begin{array}{l}\text { A OAE apresenta } \\
\text { desconforto ao } \\
\text { usuário, com defeitos } \\
\text { que requerem ações } \\
\text { de médio prazo. }\end{array}$ & $\begin{array}{l}\text { A OAE apresenta pequenas e } \\
\text { poucas anomalias, que } \\
\text { comprometem sua vida útil, } \\
\text { em região de moderada a } \\
\text { muito forte agressividade } \\
\text { ambiental ou a OAE } \\
\text { apresenta moderadas a } \\
\text { muitas anomalias, que } \\
\text { comprometem sua vida útil, } \\
\text { em região de baixa } \\
\text { agressividade ambiental. }\end{array}$ \\
\hline
\end{tabular}




\begin{tabular}{|c|c|c|c|c|}
\hline 2 & Ruim & $\begin{array}{c}\text { Há danos que } \\
\text { comprometem a } \\
\text { segurança estrutural da } \\
\text { OAE, sem risco } \\
\text { iminente. Sua evolução } \\
\text { pode levar ao colapso } \\
\text { estrutural. A OAE } \\
\text { necessita de } \\
\text { intervenções a curto } \\
\text { prazo. }\end{array}$ & $\begin{array}{l}\text { A OAE com } \\
\text { funcionalidade } \\
\text { visivelmente } \\
\text { comprometida, com } \\
\text { riscos de segurança } \\
\text { ao usuário, } \\
\text { requerendo } \\
\text { intervenções de curto } \\
\text { prazo. }\end{array}$ & $\begin{array}{l}\text { A OAE apresenta anomalias } \\
\text { moderadas e abundantes, que } \\
\text { comprometem sua vida útil, } \\
\text { em região de muito forte } \\
\text { agressividade ambiental. }\end{array}$ \\
\hline 1 & Crítica & $\begin{array}{l}\text { Há danos que geram } \\
\text { grave insuficiência } \\
\text { estrutural na OAE. Há } \\
\text { elementos estruturais } \\
\text { em estado crítico, com } \\
\text { risco tangível de } \\
\text { colapso estrutural. A } \\
\text { OAE necessita } \\
\text { intervenção imediata, } \\
\text { podendo ser necessária } \\
\text { restrição de carga, } \\
\text { interdição total ou } \\
\text { parcial ao tráfego, } \\
\text { escoramento provisório } \\
\text { e associada } \\
\text { instrumentação, ou não. }\end{array}$ & $\begin{array}{c}\text { A OAE não apresenta } \\
\text { condições funcionais } \\
\text { de utilização. }\end{array}$ & $\begin{array}{l}\text { A OAE encontra-se em } \\
\text { elevado grau de deterioração, } \\
\text { apontando problema já de } \\
\text { risco estrutural e/ou } \\
\text { funcional. }\end{array}$ \\
\hline
\end{tabular}

\section{RESULTADOS}

Analizou-se as condições patológicas encontradas nas 4 pontes com base em notas constatadas a partir dos ensaios de esclerometria, carbonatação por aspersão de fenolftaleína e o de oxidação pela penetração de íons de cloreto. Os ensaios forneceram um banco de dados das pontes para conhecimento público e está resumido a seguir.

\subsection{Ensaio de Escleometria}

A seguir, nas (Figura 13A e 13B), são apresentadas as malhas para realização do ensaio em campo, e em seguida, no (Quadro 2), são apresentadas as resistências aferidas para cada ponte. Os ensaios resultaram em valores que indicam a resistência superficial do concreto, e com isso, pode avaliar o nível de resistência a compressão bem como a integridade física da matriz de concreto.
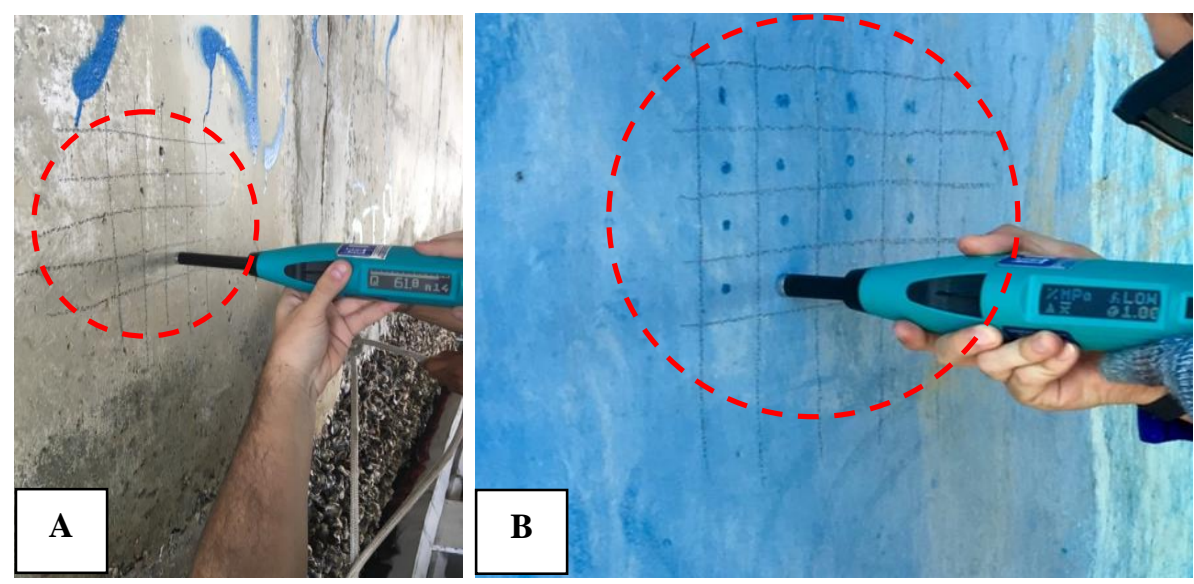

Figura 13: Ensaio esclerométrico realizado na Ponte 12 de Setembro (A); Ensaio esclerométrico realizado na Ponte José de Barros Lima (B) 
Quadro 2 - Resultados dos ensaios de esclerometria.

\begin{tabular}{|c|c|c|c|}
\hline \multirow{2}{*}{ Ponte } & \multirow{2}{*}{ Ponto } & Índices esclerométricos & Resistência \\
\cline { 2 - 4 } & 1 & $(\mathbf{I E})$ & (MPa) \\
\hline \multirow{2}{*}{ 12 de Setembro } & 2 & 66,60 & 37,50 \\
\cline { 2 - 4 } & 1 & 64,90 & 32,50 \\
\hline \multirow{2}{*}{ Princesa Isabel } & 2 & 51,50 & 33,00 \\
\cline { 2 - 4 } & 1 & 38,50 & 17,50 \\
\hline \multirow{2}{*}{$\begin{array}{c}\text { José de Barros } \\
\text { Lima }\end{array}$} & 2 & 51,50 & 33,00 \\
\cline { 2 - 4 } & & 38,50 & 17,50 \\
\hline
\end{tabular}

Os resultados indicaram uma resistência mais elevada levando em consideração a época da qual as pontes foram construídas, pois, não se era possível atingir valores da ordem de $60 \mathrm{MPa}$ de resistência à compressão devido as limitações tecnológicas.

Dessa forma, fica sob suspeita que o ataque por carbonatação esteja ocorrendo e proporcionando uma resistência maior nas superfícies das peças e permanecendo o núcleo intacto quanto a magnitude de resistência.

A análise de esclerometria constatou que o concreto está com resistência superficial satisfatória, porém, os resultados podem ter sido alterados devido a recentes reparos na estrutura.

\subsection{Profundidade de carbonatação por aspersão de fenolftaleína}

Os ensaios foram proferidos seguindo as indicações para realização dos ensaios e mensuraram a profundidade de ataque por carbonatação nos elementos de concreto armado. Abaixo, na (Quadro 3), apresenta-se o relatório fotográfico e o resultado da profundidade de ataque por carbonatação obtido nos ensaios.

Quadro 3 - Resultados dos ensaios de aspersão de fenolftaleína

\begin{tabular}{|c|c|c|c|}
\hline Ponte & Ponto & $\begin{array}{c}\text { Profundidade de } \\
\text { Carbonatação }(\mathrm{cm})\end{array}$ & Foto do Ponto Avaliado \\
\hline 12 de Setembro & 1 & $\begin{array}{c}\text { Percebeu-se que no ponto } \\
\text { onde o concreto perdeu } \\
\text { parte do seu cobrimento, } \\
\text { a presença de } \\
\text { carbonatação foi } \\
\text { confirmada até a } \\
\text { profundidade de } \\
\text { aproximadamente } 1 \mathrm{~cm}\end{array}$ & \\
\hline
\end{tabular}




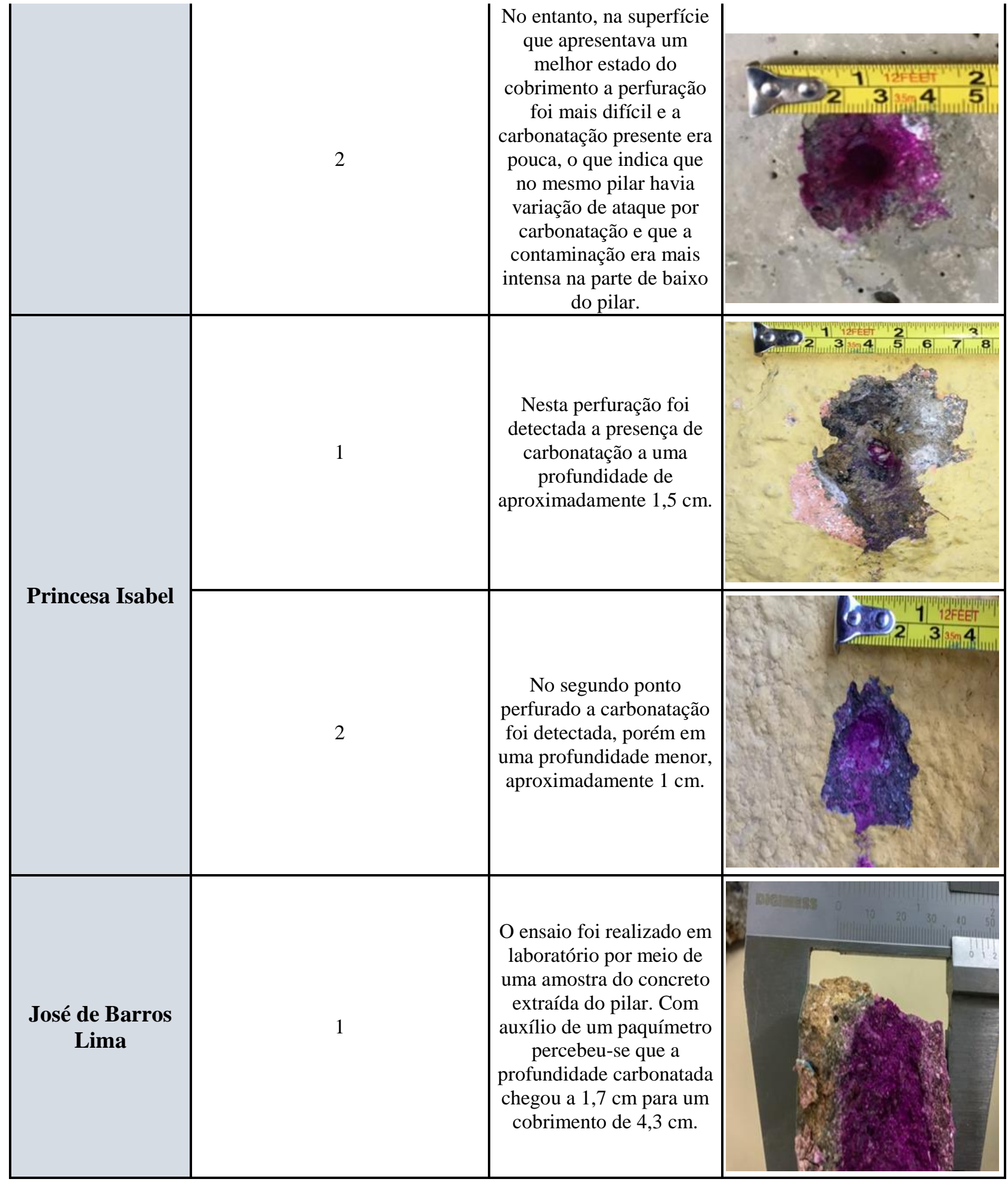

\subsection{Penetração dos Íons de Cloreto}

O local escolhido para a realização do ensaio (A) é próximo ao local onde foi realizado o ensaio de profundidade de carbonatação (B), como mostra a (Figura 14). O pilar escolhido para a perfuração apresentava fissuras, eflorescência, humidade e, consequentemente, corrosão das armaduras. Além disso, havia perdido a camada de cobrimento de concreto. 


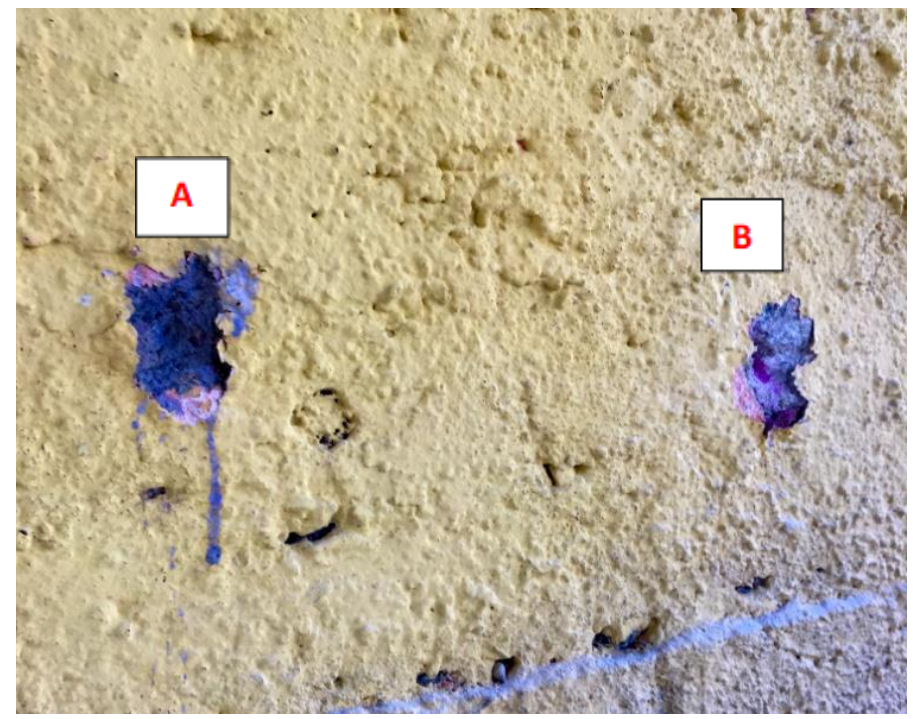

Figura 14: Exemplo de aplicação de timolftaleína

A perfuração realizada na Ponte Princesa Isabel foi de aproximadamente $2 \mathrm{~cm}$ e ficou constatada a contaminação por cloretos livres alcançando a armadura, pois até onde foi perfurado, havia a contaminação.

\subsection{Aplicação do método da análise qualitativa NBR 9452 (ABNT, 2016)}

Após as vistorias realizadas, análise do material fotográfico e resultado dos ensaios, foram mensuradas as notas segundo os critérios da norma NBR 9452 (2016), resumida abaixo no (Quadro 4).

Quadro 4 - Classificação das pontes de acordo com a NBR 9452 (2016)

\begin{tabular}{|c|c|c|c|c|c|}
\hline Ponte & $\begin{array}{c}\text { Nota de } \\
\text { classificação }\end{array}$ & Condição & $\begin{array}{c}\text { Característica } \\
\text { estrutural }\end{array}$ & $\begin{array}{c}\text { Característica } \\
\text { funcional }\end{array}$ & $\begin{array}{c}\text { Caracterização } \\
\text { de durabilidade }\end{array}$ \\
\hline $\begin{array}{c}\text { 12 de } \\
\text { Setembro }\end{array}$ & 1 & Crítica & $\begin{array}{c}\text { Há elementos estruturais } \\
\text { em estado crítico } \\
\text { necessitando } \\
\text { intervenção imediata. }\end{array}$ & $\begin{array}{c}\text { Não apresenta } \\
\text { condições } \\
\text { funcionais de } \\
\text { utilização. }\end{array}$ & $\begin{array}{c}\text { Elevado estado de } \\
\text { deterioração. }\end{array}$ \\
\hline $\begin{array}{c}\text { Princesa } \\
\text { Isabel }\end{array}$ & 2 & Ruim & $\begin{array}{c}\text { Não apresenta risco } \\
\text { iminente, mas necessita } \\
\text { intervenção a curto } \\
\text { prazo. }\end{array}$ & $\begin{array}{c}\text { Estrutura } \\
\text { visivelmente } \\
\text { comprometida. }\end{array}$ & $\begin{array}{c}\text { Apresenta } \\
\text { anomalias } \\
\text { moderadas a } \\
\text { abundantes. }\end{array}$ \\
\hline $\begin{array}{c}\text { José de } \\
\text { Barros } \\
\text { Lima }\end{array}$ & 1 & Crítica & $\begin{array}{c}\text { Há elementos estruturais } \\
\text { em estado crítico } \\
\text { necessitando } \\
\text { intervenção imediata. }\end{array}$ & $\begin{array}{c}\text { Não apresenta } \\
\text { condições } \\
\text { funcionais de } \\
\text { utilização. }\end{array}$ & $\begin{array}{c}\text { Elevado estado de } \\
\text { deterioração. }\end{array}$ \\
\hline
\end{tabular}

\section{CONCLUSÕES}

Com base no estudo proposto e levando em consideração todos os métodos utilizados para a análise das manifestações patológicas das pontes, é evidente que as mesmas não passaram por um processo de recuperação e/ou reparo comprometendo a vida útil e a durabilidade dessas obras.

Essas estruturas estão localizadas em ambientes que possue classe de agressividade IV de acordo com a NBR 6118 e apresentou manifestações patológicas que comprometem sua vida útil, durabilidade e, sobretudo, a funcionalidade, pois essas pontes tem a função de interligar os estremos da cidade.

Os ensaios realizados para análise comportamental das pontes são de suma importância, pois a os mesmos trouxeram resultados satisfatórios: 
- No ensaio de esclerometria observou-se que a na ponte 12 de Setembro a resistência superficial do concreto variava entre 65 à $68 \mathrm{MPa}$. Esses resultados afirmam que as pontes posseum uma resistência superficial considerada boa apesar de apresentar manifestações patológicas como fissuras, eflorescência e oxidação.

- Nas pontes Princesa Isabel e José de Barros Lima os resultados da resistência superficial do concreto foram praticamente iguais variando entre 17 a $35 \mathrm{MPa}$, onde evidencia que estas devem possuir um projeto de recuperação com urgência.

- Em relação a profundidade de carbonatação observou-se que a Ponte 12 de setembro teve um melhor comportamento quando se aspeliu a fenolftaleína. $\mathrm{O} \mathrm{CO}_{2}$ incidiu $1 \mathrm{~cm}$. Em relação as outras duas pontes essa profundidade foi $59 \% \mathrm{com} 1,5$ e $1,7 \mathrm{~cm}$.

- O ensaio de penetração de íons cloretos foi realizado apenas na Ponte 12 de Setembro e percebeu-se que quando foi aspelida a timolftaleína alguns picos estavam incolor afirmando a presença de sais na estrutura, além de afetar as armaduras causando corrosão pontual.

Assim, para que se tenha uma obra dessa plenitude em perfeito estado deve-se aplicar as técnicas definidas pela norma que mantenha as funcionalidades físicas e mecânicas nos aspéctos de durabilidade e vida útil.

\section{REFERÊNCIAS}

ABNT - Associação Brasileira de Normas Técnicas. NBR 6118: Projeto de estruturas de concreto - procedimento. Rio de Janeiro, 2014.

ABNT - Associação Brasileira de Normas Técnicas. NBR 7584: Concreto endurecido - Avaliação da dureza superficial pelo esclerômetro de reflexão - Método de ensaio. Rio de Janeiro: 2012. 10 p.

ABNT - Associação Brasileira de Normas Técnicas. NBR 9452: Inspeção de pontes, viadutos e passarelas de concreto - procedimento. Rio de Janeiro, 2016.

DIÓGENES, A.; SANTOS, M.; BRANDÃO, F.; BRAGA, W. Manifestações Patológicas em Pontes da Cidade de Sobral-CE. In: CONGRESO INTERNACIONAL SOBRE PATOLOGÍA Y RECUPERACIÓN DE ESTRUCTURAS, 10., 2014, Santiago. Anais... Santiago: Cinpar, 2014. p. 1 - 12.

DNIT. Norma 122: Pontes e viadutos rodoviários - Estruturas de concreto armado - Especificação do serviço. Rio de Janeiro, 2009.

NASCIMENTO, C. F. G.; SOUZA, P. M. C. O.; SILVA, T. M.; SANTOS, M. S. C.; VALÕES, D. C. P.; FIGUEIRA, A. M. A.; CAVALCANTI, L. R.; PASSOS NETO, G. M.; MONTEIRO, E. C. B. Utilização do método dos fatores para priorização de incidências patológicas na ponte Barão de Jundiá, 48 anos de construção no município de EscadaPE. Revista Científica Semana Acadêmica, ceará, v. 01, n. 176, p.1-17, ago. 2019.

MILANI, C; KRIPKA, M; PRAVIA, Z. (2015), Monitoramento de pontes. Revista infraestrutura urbana. PINI: São Paulo, 16. ed, 2011.

RILEM RECOMMENDATIONS. CPA-18 Measurement of hardened concrete carbonation depfh. Ano 1988.

VITÓRIO, A. Pontes Rodoviárias. Recife: CREA-PE, 2002.

VITÓRIO, J. A. P.; BARROS, R. M. M. C. Análise dos danos estruturais e das condições de estabilidade de 100 pontes rodoviárias no brasil. In: CONGRESSO DA ASSOCIAÇÃO PORTUGUESA PARA A SEGURANÇA E CONSERVAÇÃO DE PONTES, 3, 2013, Porto. Anais... Porto, 9p. 